\title{
PROBLEMA
}

\section{THE AMERICANS WITH DISABILITIES ACT AND HEALTH CARE ALLOCATION}

\author{
Iwao HIROSE
}

Resumen:

En este artículo propongo un argumento teórico para prohibir el trato desigual entre personas discapacitadas y no discapacitadas en la distribución de recursos médicos. En primer lugar analizaré un argumento que apoya un trato desigual, el cual fue presentado por Singer y otros, y trataré de establecer sus alcances. Después utilizaré ese mismo argumento para derivar otro que nos llevaria a prohibir el trato desigual entre discapacitados y no discapacitados en casi todos los casos de distribución de recursos médicos.

\section{Palabras Clave:}

Discriminación, atención médica, salud pública, discapacitados.

\begin{abstract}
:
In this article, I will propose a theoretical argument for the prohibition of unequal treatment of disabled and non-disabled individuals in health care resource allocation. I will first consider an argument for unequal treatment, which was put forward by Singer et al, and elucidate its far-reaching scope. I will then use the same argument in order to derive an argument that would prohibit unequal treatment of disabled and non-disabled individuals in almost all cases of health care allocation.
\end{abstract}

Keywords:

Discrimination, Health Care Allocation, Public Health, Disabled People. 
Summary: I. Introduction. II. How does Unequal Treatment Occur in Health Care? III. An Argument for the Permissibility of Disability Discrimination in Health Care. IV. How Should We Argue Against Disability Discrimination? V. Critique of the Melburnians' Argument. VI. Conclusion. VII. References.

\section{INTRODUCTION}

The Americans with Disabilities Act (ADA) of 1990 defines a disability as "a physical or mental impairment that substantially limits a major life activity", and prohibits discrimination on the basis of disability in employment, public services, transportation, and public communication. The ADA does not prohibit every form of unequal treatment of the disabled and non-disabled. It is perfectly justifiable that NFL teams employ no players with a disability insofar as they do not clearly state that no disabled individuals are allowed to apply for vacant positions. Teams consider the skills and performance of players, and hire players on the basis of skills and performance. Even if there are no players with a disability in a football game, we do not see this fact as a case of disability discrimination. Similar things can be said about the distribution of medical resources between different patients. Doctors can choose to give a treatment to a non-disabled patient rather than a disabled patient if the non-disabled patient arrived at the hospital earlier or his medical need is more urgent. Insofar as the decision is made on a principle that is justifiable in its own light (i.e. 'first come, first served', or the principle of urgency), the unequal treatment of different patients is not seen as wrongful discrimination, even if the patient with a disability happens to receive lower priority.

Here is a general question concerning the scope of the ADA. What sort of unequal treatment on the basis of disability counts as wrongful discrimination that the ADA should regulate? This question is the motivation for this paper. 
However, I do not attempt to answer this general question. ${ }^{1}$ Rather, I want to consider the following specific question: Would unequal treatment of disabled and non- disabled individuals in health care be a type of wrongful discrimination that the ADA should regulate? If not all forms of unequal treatment between the disabled and non-disabled patients are unjust or unfair, and if there is a compelling argument for the permissibility of such unequal treatment, then there would be reason to eliminate it from the category of wrongful discrimination that the ADA prohibits.

Intuitively, unequal treatment on the basis of disability is unjust and/or unfair in health care, and it therefore appears to be a form of discrimination that we ought to avoid. As a matter of fact, the ADA is understood to prohibit unequal treatment on the basis of disability in health care. ${ }^{2}$ Yet it is not entirely clear whether this intuition is normatively plausible. Several philosophers have offered normative arguments for the permissibility of unequal treatment on the basis of disability in health care. The most powerful of these was proposed by Singer et al (1995) and put forward by McKie et al (1998). Their argument is often criticized on the grounds that unequal treatment on the basis of disability in health care is in fact a form of wrongful discrimination, rather than by establishing that such treatment cannot be justified. This sort of assertion, however, is not supported by a plausible normative argument. As far as I can see, there is no effective normative criticism against the normative argument for the permissibility of unequal treatment of disabled and non-disabled patients. In this paper, I will propose a normative argument against unequal treatment in health care on the basis of disability by virtue

1 For the general definition of discrimination, see Alexander (1992) and Lippert-Rasmussen (2006).

2 See Brock $(1995,2000,2006)$ concerning how the US federal health authority rejected Oregon's application for a type of MedicAid administration that may entail the unequal treatment of disabled and non-disabled patients. For the reaction of medical ethicists to "Oregon's denial", see Hadorn (1992), Menzel (1992), and Orentlicher (1994). 
of criticising the argument first made in Singer et al (1995). I will accept their theoretical framework but derive an argument against the permissibility of unequal treatment on the basis of disability in health care. I believe my discussion can offer an effective criticism of their powerful argument.

This paper is organized as follows. In section II, I will explain how the unequal treatment of disabled and non-disabled individuals occurs in health care resource allocation. In section III, I will elucidate the theoretical structure of the arguments in Singer et al. in favour of unequal treatment. In section IV, I will discuss how we should argue against unequal treatment of disabled and non-disabled patients. In section $\mathrm{V}$, I will propose a normative argument against unequal treatment in health care on the basis of disability without rejecting the theoretical framework of Singer et al.

\section{How does Unequal Treatment Occur in Health Care?}

Unequal treatment of disabled and non-disabled patients in health care can occur when and because a certain method of priority-setting is employed in order to decide how we allocate scarce resources amongst different patients. Health care resources (money, facilities, equipment, time, personnel, donors, medicine, and so on) are usually scarce. When we cannot treat every patient, we encounter difficult choices concerning whom we should and should not treat. At the level of a national health care system, one of the main principles is the principle of maximizing benefits from health interventions. But how do we measure health benefits? In many countries, health benefits are measured by Quality Adjusted Life Years (QALYs). QALYs combine two types of benefit from health interventions. First type is the number of years of life saved. The second type is changes to health-related quality of life. According to the principle of QALY maximization, our health care system gives priority to those whose life is extended most and/or 
whose quality of life is improved most. According to this principle, we discriminate patients by gains in QALYs.

As I wrote earlier, according to the ADA, an individual with a disability is "a person who has a chronic physical or mental impairment that substantially limits one or more major life activities". Since disabilities by definition limit one or more major life activities, they will reduce an individual's health-related quality of life, and health interventions will produce fewer QALYs for a disabled patient than for an otherwise similar non-disabled patient. Furthermore, the presence of a disability, or a more severe disability, can often make treatment more complex or extended, and thus more expensive, than it would be for someone without a disability or with one that is less severe. Thus, given the same amount of health care resources, an individual with a disability produces fewer QALYs than an individual with no disability.

Since (a) we use the QALY measure to allocate health care under the condition of scarce resources and (b) disabled people produce fewer QALYs than non-disabled people, we give greater priority to the non-disabled over the disabled in a systematic way, and we thus treat disabled and non-disabled people unequally. As smaller priority is given to disabled individuals in a systematic way, unequal treatment on the basis of disability in health care is allegedly a form of disability discrimination in the area of health care. ${ }^{3}$ Let me explain this with an example.

Saving the non-disabled: Suppose that there are two seriously ill patients and that we can treat only one of them. Let us assume that each will die immediately without the treatment, and that each will live for 20 years with the treatment. The only difference between the two patients is that patient A has been, and will continue to be, confined to a wheelchair and patient $\mathrm{B}$ does not, and will not, have any disabil-

3 For more elaborated discussion of how disability discrimination occurs in health care, see Brock (1995, 2000, 2006), Harris (1987), Kamm (2004, 2006), and Nord (1999). 
ity. All other features are assumed to be equal. According to the maximization of QALYs, it is better to offer the treatment to B. Even though each will live for exactly the same number of years, A's health-related quality of life is strictly lower than B's because A's disability is by definition a loss in health-related quality of life.

It is clear that the definition of disability and the principle of QALY maximization jointly lead us to the alleged disability discrimination in health care. Given that a disability is a loss in health-related quality of life, even if the life of the patient with a disability is saved, his health-related quality of life does not reach the normal level of functioning. On the other hand, if we give the treatment to the patient with no disability, she can reach the normal level of functioning. Insofar as we adopt the principle of QALY maximization, the health benefit is maximized if we offer the treatment to the patient with no disability. This is how the alleged disability discrimination arises in health care.

I have two brief remarks that should elucidate the scope of the alleged disability discrimination in health care. First, it is not claimed that the individual with a disability has a life not worth living. The maximization of QALYs is concerned with health-related quality of life, not overall quality of life. The notion of disability is defined in terms of health condition, and QALYs combine the extension of life-years and the improvement in health-related quality of life. The loss in the health-related quality of life does not mean that individuals with disabilities are inferior to individuals with no disabilities, all things considered. Individuals with disabilities may well have a higher level of all-things-considered quality of life than individuals with no disabilities. Thus, it is not disrespectful to disabled people to say that their health-related quality of life is lower than that of non-disabled people.

Second, there is no necessary relation between the maximization of QALYs and the lower priority given to the patients with disabilities. In principle, there can be cases in 
which the maximization of QALYs would function in favour of patients with disabilities. ${ }^{4}$ Suppose that there are two patients with the same disease, one with a disability and the other with no disability, and that if we give a treatment to the patient with the disability, the disability is cured as a side effect of that treatment. In this case, the maximization of QALYs tells us to treat the patient with the disability, because the benefit from the disability-cure tips the balance in favour of the patient with the disability.

\section{An ARgument For the PeRmissibility of Disability Discrimination IN HEAlTH CARE}

The most robust ethical argument for the permissibility of disability discrimination in health care was first proposed by Singer, McKie, Kuhse and Richardson (1995) and then elaborated by McKie, Richardson, Singer, and Kuhse (1998). Hereafter, I will use a general term to refer to these authors, and call them the Melburnians because they all worked at Monash University in Melbourne.

The Melburnians contend that we can decide whether social arrangements are just by asking if these arrangements would be agreed to by rational egoists choosing from behind a veil of ignorance, where people are deprived of knowledge concerning whether they will be advantaged or disadvantaged by the proposed arrangements. The Melburnians then invite us to imagine a hypothetical social choice situation where two rational egoists each need life-saving treatment and have an interest in continued life, but there is enough life-saving treatment for only one of them. To maximise the satisfaction of their own interests, the rational egoists would have to choose a principle that gives preference to saving life when it is most in the interests of the person whose life is saved. This means that if QALYs are an accu- 
rate way of measuring wich life maximizes one's interests, then egoists would rationally choose to allocate resources in accordance with the principle of QALY maximization. According to the Melburnians, the principle of QALY maximization is justifiable as a principle of health care resource allocation, and the unequal treatment on the basis of disability that would result from the use of this principle is also justifiable. This is what the Melburnians contend.

Here is a reason why I believe their argument is strong. Proponents of utilitarianism would support the Melburnians' claim. But so would proponents of other distributive principles such as Prioritarianism and some types of egalitarianism (e.g. what Derek Parfit calls Telic Egalitarianism). ${ }^{5}$ Note that the Melburnians' (1995) argument is more modest than John Harsanyi's (1955, 1977) case for average utilitarianism, even though they both appeal to the rational choice of egoists in a hypothetical situation. The Melburnians do not claim that individuals behind the veil of ignorance would rationally choose average utilitarianism. Harsanyi makes two claims. ${ }^{6}$ The first claim is that if individual and social preferences satisfy the expected utility axioms and if the social welfare function satisfies a Pareto condition, then social utility must be represented by a weighted sum (precisely, an affine transformation) of individual utilities (the Aggregation Theorem). The second claim is that if individuals are placed behind the veil of ignorance, then they will rationally believe that each of them has an equal chance of being in any of these positions, and hence that the weight of each individual's utility must be $1 / n$ in the $\mathrm{n}$-person society (the Impartial Observer Theorem). The notion of the veil of ignorance is used for the second claim. That is, in Harsanyi's argument, the veil of ignorance is meant to offer grounds for average utilitarianism.

5 See Parfit (1995) for Prioritarianism, and [Hirose, Iwao (2009), "Reconsidering the Value of Equality", Australasian Journal of Philosophy, 87] for a version of Telic Egalitarianism that satisfies the Pareto condition.

6 See Weymark (1991). 
On the other hand, the Melburnians (1995) merely claim that individuals behind the veil of ignorance would rationally choose a principle that advances every individual's interest. That is, individuals would rationally choose a principle that satisfies the strong Pareto principle. The strong Pareto principle holds that if one alternative is better for someone than another alternative and worse for no one, then it is better than the other. Imagine that two individuals are placed behind the veil of ignorance in order to choose two possible states of affairs $\mathrm{x}=(5,8)$ and $\mathrm{y}=(10,5)$, where the brackets show the states of the two individuals. Given that two individuals do not know which position they will occupy in $\mathrm{x}$ and $y$, each of them would rationally judge that $x=(5,8)$ is just as good as $x^{\prime}=(8,5)$. By the strong Pareto principle, they would judge that $y=(10,5)$ is strictly better than $x^{\prime}=(8,5)$. Hence, they would judge that $\mathrm{y}$ is strictly better than $\mathrm{x}$. Needless to say, this judgment is supported by average and classical utilitarianism. But it is also supported by other consequentialist principles. Prioritarianism and some versions of Telic Egalitarianism support such a judgment. Some non-aggregative principles, such as the lexicographic extension of the maximin rule (i.e. leximin), also support it. ${ }^{7}$ Therefore, the Melburnians' argument for QALYs can be supported not only by proponents of utilitarianism but also by some opponents of utilitarianism. This is why their argument is so powerful. 8

7 Leximin first compares the worst off across alternatives and, if the worst off are at the same level, compares the second worst off, and so on. Notice that Maximin, which judges the relative goodness of alternatives only by the worst off across alternatives, does not satisfy the strong Pareto principle.

8 In their later work, the Melburnians (1998) implicitly suggest that rational egoists would choose a form of utilitarianism that gives an equal weight to each individual's interest. However, this is not necessary to justify the case for the maximization of QALYs, and undermines the scope of their initial argument. Therefore, in what follows, when I discuss the Melburnians' argument, I refer to their argument as presented in 1995. 


\section{How Should We Argue Against Disability}

\section{DISCRIMINATION?}

Intuitively, many people find it hard to accept the permissibility of disability discrimination in health care. One way to argue against the permissibility of disability discrimination in health care is to claim that it is not permissible in a bold way. For example, it may take the form of modus ponens.

(1) Unequal treatment of disabled and non-disabled individuals should be prohibited in general.

(2) If unequal treatment of disabled and non-disabled individuals should be prohibited in general, then unequal treatment of disabled and non-disabled individuals should be prohibited in health care.

Therefore, unequal treatment of disabled and non-disabled individuals should be prohibited in health care.

I believe that many people who think alleged disability discrimination in health care is implausible have this sort of reasoning in mind. But this is too bold. In the issue under consideration, premise (2) cannot be assumed to be true. Premise (2) is precisely what we have been discussing. The Melburnians would disagree with premise (2), because even if the antecedent of premise (2) is true, the consequent does not follow, given their argument that I outlined in the previous section. Their argument is constructed for the purpose of defusing premise (2). The ADA prohibits discrimination on the basis of disability in employment, public services, transportation, and public accommodations. Many people including the Melburnians would agree with this. However, the question under consideration is whether disability discrimination in health care is a type of wrongful discrimination that the ADA should prohibit. The Melburnians argue that it is not. They would claim that the consequent does not follow from the antecedent. Therefore, opponents of disability discrimination in health care must 
establish the logical relation of the antecedent and consequent in premise (2) in order to support their bold intuition.

Many opponents simply believe that disability discrimination in health care is a type of wrongful discrimination that does not require a normative argument. It is possible that the belief of these opponents is supported by some non-normative elements such as social psychology and opinion polls. For example, Alan Williams simply says "[a]t the end of the day we simply have to stand up and be counted as to which set of principles we wish to have underpin the way the health care system works". ${ }^{9}$

The Melburnians show some sympathy for these sorts of non-normative elements. But they clearly illustrate that such beliefs are not supported by an underlying normative argument.

In a recent survey of the attitudes of Australians to the distribution of health care, we found that many respondents were ready to depart from QALY maximisation in order to avoid prioritizing the treatment of some patients over others, and this may also be explained by a concern for how a direct maximisation approach effects the kind of society we are. ... It is at least possible that Australians (and no doubt some other nationals as well) consider it important to act in ways that go beyond abstract justice or fairness, instead tilting the balance so that it favours those who would otherwise feel arbitrarily disadvantaged. On these grounds, we could understand a preference for avoiding double jeopardy, even though double jeopardy [alleged disability discrimination in health care] is not in itself unjust or unfair. 10

In what follows, I will present my normative argument against the Melburnians' normative argument for the permissibility of disability discrimination in health care. I will take the following strategy. For the sake of argument, I will accept the theoretical framework of the Melburnians, but I will

9 Williams (1987, 123).

10 Singer et al. $(1995,150)$. 
use their framework to derive an argument against disability discrimination in health care.

\section{Critique of the Melburnians' Argument}

Suppose that two individuals are placed behind the veil of ignorance: one with a disability and the other with no disability. ${ }^{11}$ They do not know which position either will occupy when the veil of ignorance is lifted. Now consider table 1. The brackets show the health conditions of the two individuals. We are to choose either prospect A or B. Each prospect consists of two possible outcomes, which are assumed to be equally probable. If we choose prospect $A$, we give the treatment to the non-disabled patient and let the disabled patient die, regardless of whether the coin lands heads or tails. If we choose prospect $B$, we give an equal chance of treatment to the disabled and non-disabled patients. Given (a) that heads and tails are equally probable and (b) that the two individuals do not know which position they will occupy, the expected good of prospect A is strictly greater than that of $\mathrm{B}$ (more precisely, prospect A dominates prospect $B$ ). Therefore, according to the Melburnians, two individuals would rationally choose prospect A.

Table 1

\begin{tabular}{|l|l|l|}
\hline & $\begin{array}{l}\text { Prospect A } \\
(\text { Disabled, Non-Disabled) }\end{array}$ & $\begin{array}{l}\text { Prospect B } \\
\text { (Disabled, Non-Disabled) }\end{array}$ \\
\hline Heads & $(0,1)$ & $(0,1)$ \\
\hline Tails & $(0,1)$ & $(0.6,0)$ \\
\hline
\end{tabular}

I disagree. There is a good reason to choose prospect B, in which case we give an equal chance to the disabled individual and non-disabled individual. How can prospect $B$ be

11 The following argument is an extension of Diamond's (1967) counter-example to Harsnayi's case for average utilitarianism. 
strictly better than prospect A if we accept the Melburnians' theoretical framework? It is because prospect A is unfair to the person who would occupy the position of the disabled individual. By unfairness, I mean a situation where one person receives no chance of receiving some benefit while another person receives some chance. I do not contend this is the only correct way to spell out the notion of unfairness. But I believe it captures one feature of unfairness, and this allows me to use this normative word here.

To further illustrate my point, consider table 2 where both patients can regain the normal level of functioning. According to the Melburnians, prospect A is just as good as B. But I believe that prospect B' is strictly better than A, and that many people would agree with me.

Table 2

\begin{tabular}{|l|l|l||}
\hline & $\begin{array}{l}\text { Prospect A } \\
(\mathrm{X}, \mathrm{Y})\end{array}$ & $\begin{array}{l}\text { Prospect B' } \\
(\mathrm{X}, \mathrm{Y})\end{array}$ \\
\hline Heads & $(0,1)$ & $(0,1)$ \\
\hline Tails & $(0,1)$ & $(1,0)$ \\
\hline
\end{tabular}

Why is prospect B' strictly better than A? Because, in prospect $A$, the individual who will occupy the position of $\mathrm{X}$ is deprived of the chance to receive any benefit, whereas the other individual, who will occupy the position of Y, receives the benefit for certain. Therefore, prospect $A$ is not fair to the person-position X and prospect B' is fair to each person-position. We do not know who will occupy X's position, but there is one person-position that is treated unfairly if we choose prospect A. So there is a morally relevant feature that is not captured in table 2. Table 2 should be rewritten as table 3.12

12 For different ways of capturing the notion of unfairness in this example, see Broome (1990-1991), and Segall and Epstein (1992). Hirose (2004) and Karni and Safra (2002) consider how the disvalue of unfairness can be measured. 
IWAO HIROSE

Table 3

\begin{tabular}{|l|l|l|}
\hline & $\begin{array}{l}\text { Prospect A } \\
(\mathrm{X}, \mathrm{Y})\end{array}$ & $\begin{array}{l}\text { Prospect B' } \\
(\mathrm{X}, \mathrm{Y})\end{array}$ \\
\hline Heads & $(0-$ Unfairness, 1$)$ & $(0,1)$ \\
\hline Tails & $(0$-Unfairness, 1$)$ & $(1,0)$ \\
\hline
\end{tabular}

In table 3, unfairness to the person-position $\mathrm{X}$ is included as the negative component. The disvalue of unfairness is not a health benefit, and does not reduce the value of health benefit. Therefore, I do not subtract it from the expected value of health benefits. But it is considered together with the expected value of health benefits. Table 3 explains why prospect B' is strictly better than A.

Let's go back to table 1 . Just like table 2, I believe table 1 does not capture the consideration of unfairness. Table 1 should be rewritten as follows.

Table 4

\begin{tabular}{|l|l|l|}
\hline & $\begin{array}{l}\text { Prospect A } \\
\text { (Disabled, Non-Disabled) }\end{array}$ & $\begin{array}{l}\text { Prospect B } \\
\text { (Disabled, Non-Disabled) }\end{array}$ \\
\hline Heads & $(0$ - unfairness, 1) & $(0,1)$ \\
\hline Tails & $(0$-unfairness, 1) & $(0.6,0)$ \\
\hline
\end{tabular}

In table 4 , the judgement of our rational individuals depends on the disvalue of unfairness. ${ }^{13}$ If and only if the disvalue of unfairness outweighs the difference in the expected good of the health condition, prospect $B$ is judged to be

13 The Melburnians (1995) do not assume that the chance of occupying each person's position is equal. Suppose that the chance of occupying the disabled person's position is $\mathrm{p}(0<\mathrm{p}<1)$. The chance of occupying the non-disabled person's position is therefore $(1-\mathrm{p})$. Let $\mathrm{U}$ denote the disvalue of unfairness. The expected good of each prospect is calculated in the following manner.

$\mathrm{GA}=1 / 2\{(0-\mathrm{U}) \times \mathrm{p}+1 \times(1-\mathrm{p})\}+1 / 2\{(0-\mathrm{U}) \times \mathrm{p}+1 \times(1-\mathrm{p})\}$

$\mathrm{GB}=1 / 2\{0 \times \mathrm{p}+1 \times(1-\mathrm{p})\}+1 / 2\{0.6 \times \mathrm{p}+0 \times(1-\mathrm{p})\}$.

This means that prospect $A$ is as good as B if and only if $U=1 /(2 p)-0.8$. 
strictly better than prospect A. In this case, individuals would rationally choose to give an equal chance of survival to the disabled and non-disabled. Otherwise, individuals would choose prospect $\mathrm{A}$, and agree to give the treatment to the non-disabled. If the disvalue of unfairness is large enough, we would rule out almost all cases of disability discrimination in health care. It all depends on how much disvalue we attach to the notion of unfairness.

The upshot of my argument is this. For the sake of argument, I agree with the Melburnians' general theoretical framework: the choice concerning whom to save in health care can be justified insofar as the principle of health care resource distribution would be chosen by rational egoists behind the veil of ignorance. However, rational egoists in this choice situation would consider not only their healthrelated interests but also whether their health-related interests would be considered fairly. Being considered fairly is a sort of benefit that egoists would take seriously. My argument holds that adopting the QALY approach does not necessarily entail the simple maximization of QALYs, but at least the maximization of QALYs and fairness.

Three remarks are in order. First, there remains the difficult question concerning how we estimate the disvalue of unfairness. I do not have a satisfactory answer. Ultimately, we must appeal to our intuition. Second, my proposed argument remains within the Melburnians' theoretical framework, but offers a possibility of equal treatment amongst the disabled and non-disabled individuals in health care. This means that I accept the force of the modus ponens argument for disability discrimination in health care, but that I use the same argument to constrain disability discrimination in health care. In this respect, my argument has a significant theoretical advantage. Third, it may appear unsatisfactory to those who maintain the absolute prohibition of disability discrimination in health care. This is because, on my view, there can be some cases where the expected good of a health condition could outweigh the disvalue of disabil- 
ity discrimination. For example, it is possible that my argument allows such discrimination when an individual has a severe disability. The mere possibility of discrimination in such a situation may make my argument implausible for some. But, in order to support an absolute prohibition on disability discrimination in health care, we must appeal to some version of the non-normative reasons described in section 3. The crucial point is that the Melburnians' argument supports disability discrimination even if the disability is small, whereas my proposed argument allows such discrimination only in the cases where disability is severe enough.

\section{CONCLUSION}

I presented a normative argument against disability discrimination in health care in such a way that the most powerful normative argument for disability discrimination in health care is defused. However, my argument does not commit to the absolute prohibition of disability discrimination in health care. Provided my argument holds that the disabled and non-disabled patients should be treated equally in many cases, it would be practically effective if we understand the ADA to prohibit disability discrimination in health care in principle. There will be some exceptional cases where unequal treatment of disabled and non-disabled patients is normatively permissible, if the disability is severe enough. But few laws disallow exceptional cases. Therefore, cases of severe disability should be treated as exceptions.

\section{REFERENCES}

ALEXANDER, Larry (1992), "What Makes Wrongful Discrimination Wrong?" University of Pennsylvania Law Review, 141. 
BROCK, Dan (1995), "Justice and the ADA: Does Prioritizing and Rationing Health care Discriminate against the Disabled?”, Social Philosophy and Policy, 12.

(2000). "Health Care Resource Prioritization and Discrimination against Persons with Disabilities", in FRANCIS, Leslie and SILVERS, Anita (eds.) Americans with Disabilities: Implications for Individuals and Institutions. Routledge.

(2006), "Cost-effectiveness and Disability Discrimination", manuscript. Harvard University.

BROOME, John (1990-91), "Fairness", Proceedings of the Aristotelian Society, 91.

DiAmond, Peter A. (1967), "Cardinal Welfare, Individualistic Ethics and Interpersonal Comparisons of Utility: Comment", Journal of Political Economy, 75, 765-6.

HADORN, David (1992), "The Problem of Discrimination in Health Care Priority Setting", Journal of the American Medical Association, 268.

HARRIS, John (1987), "QALYfying the Value of Human Life", Journal of Medical Ethics, 13, 117-123.

- (1995), "Double Jeopardy and the Veil of Ignorance a Reply", Journal of Medical Ethics, 21, 151-157.

HARSANYI, John (1955), "Cardinal Welfare, Individualistic Ethics and Interpersonal Comparisons of Utility", Journal of Political Economy, 63, 309-21.

(1977), Rational Behavior and Bargaining Equilibrium in Games and Social Situations, Cambridge, Cambridge University Press.

HIROsE, Iwao (2004), "Aggregation and numbers", Utilitas, 16.

KamM, Frances (2004), "Deciding Whom to Help, Health-Adjusted Life Years, and Disabilities", in Sudhir Anand, Fabienne Peter and Amartya Sen (eds.), Public Health, Ethics, and Equity, Oxford University Press. 
(2006), "Disability, Discrimination and Irrelevant Goods", manuscript. Harvard University.

KAPPEL, Klemens and SANDOE, Peter (1992), "QALYs, age and Fairness," Bioethics, 6, 297-316.

KARNI, Edi and Zfi Safra. (2002). "Individual Sense of Justice: A Utility Representation", Econometrica, 70, 263-284.

LIPPERT-RASMUSSEN, Kasper (2006), "The Badness of Discrimination", Ethical Theory and Moral Practice, 9.

MCKIE, John, RICHARDSOn, Jeff, SInGER, Peter and KuHSE, Helga (1998), The Allocation of Health Care Resources: An Ethical Evaluation of the QALY Approach, Dartmouth, Ashgate.

MCMAHAN, Jeff (2005), "Causing disabled people to exist and causing people to be disabled", Ethics, 116.

MEnZEL, Paul T. (1992), “Oregon's Denial: Disabilities and Quality of Life", Hastings Center Report, 22.

NORD, Erik (1999), Cost-Value Analysis in Health Care. Cambridge, Cambridge University Press.

ORENTLICHER, David (1994), "Rationing and the Americans with Disabilities Act", Journal of the American Medical Association, 271.

PARFIT, Derek (1995), Equality or Priority?, University of Kansas, Lindley Lecture. Reprinted in CLAYTON, M. and Williams, A. (eds.) The Ideal of Equality, Basingstoke, Palgrave Macmillan (2000).

SEGALL, Uzi and EPSTEIN, Larry, G. (1992), "Quadratic social welfare functions", Journal of Political Economy, 100, 691-712.

Singer, Peter, MCKIE, John, KuHSE, Helga and Richardson, Jeff (1995), "Double Jeopardy and the Use of QALYs in Health Care Allocation", Journal of Medical Ethics, 21, 144-150. 
WEYMARK, John (1991), "A Reconciliation of the Harsanyi-Sen Debate on Utilitarianism", in ELSTER, John and ROEMER, John E. (eds.), Interpersonal Comparison of Well-Being, Cambridge, Cambridge University Press.

WILLIAMS, Allan (1987), "Response: QALYfying the value of life", Journal of Medical Ethics, 13, 123. 